\title{
HIV-Associated Lung Cancer in the Era of Highly Active Antiretroviral Therapy (HAART)
}

\author{
Suchita Pakkala ${ }^{1}$, Zhengjia Chen ${ }^{2}$, David Rimland ${ }^{3}$, Taofeek K. Owonikoko ${ }^{4}$, Clifford \\ Gunthel $^{3}$, Johann R. Brandes ${ }^{4}$, Nabil R. Saba ${ }^{5}$, Dong M. Shin ${ }^{6}$, Walter J. Curran Jr ${ }^{7}$, Fadlo \\ R. Khuri ${ }^{6}$, and Suresh S. Ramalingam ${ }^{5}$ \\ Department of Hematology and Medical Oncology Emory University School of Medicine Winship \\ Cancer Institute, Atlanta, GA. \\ ${ }^{1}$ Instructor, Department of Hematology and Medical Oncology \\ ${ }^{2}$ Assistant Research Professor of Biostatistics and Bioinformatics \\ ${ }^{3}$ Professor, Division of Infectious Disease \\ ${ }^{4}$ Assistant Professor, Department of Hematology and Medical Oncology \\ ${ }^{5}$ Associate Professor, Department of Hematology and Medical Oncology \\ ${ }^{6}$ Professor, Department of Hematology and Medical Oncology \\ ${ }^{7}$ Professor, Department of Radiation Oncology
}

\begin{abstract}
Background-Lung cancer is the leading cause of death among non-acquired immunodeficiency syndrome (AIDS) defining malignancies. Since highly active anti-retroviral therapy (HAART) has improved survival for human immunodeficiency virus (HIV) patients, we evaluated lung cancer outcomes in the HAART era.
\end{abstract}

Methods-HIV-positive patients diagnosed with lung cancer in our institution during the HAART era (1995-2008) were analyzed. Patient charts were reviewed for clinical and laboratory data. CD4 count at diagnosis was treated as a continuous variable and subcategorized into distinct variables with 3 cut-off points $(50,200, \& 500 \mu \mathrm{l})$. Pearson's correlation coefficients were estimated for each covariate studied. Survival was determined by the Kaplan-Meier method.

Results-Out of 80 patients, 73 had non-small cell lung cancer. Baseline characteristics were: median age-52 yrs; male-80\%; African American-84\%; injection drug use-25\%; smokers-100\%; and prior exposure to antiretroviral agents-55\%. Mean CD4 count and viral load were $304 \mu \mathrm{L}$ and 82,420 copies $/ \mathrm{ml}$, respectively at cancer diagnosis. The latency between diagnosis of HIV and lung cancer was significantly shorter in women ( 4.1 yrs vs. $7.7 \mathrm{yrs}, \mathrm{P}=0.02)$ and $71 \%$ of the patients received anti-cancer therapy. The 1 - and 3 -year survival rates were $31 \%$ and $4 \%$ overall. Grade $3 / 4$ toxicities occurred in $60 \%$ with chemo-radiation vs. $36 \%$ with chemotherapy. Cancerrelated survival was better for patients with $\mathrm{CD} 4$ count $>200(\mathrm{P}=0.0298)$ and $>500(\mathrm{P}=0.0076)$.

Conclusions-The latency from diagnosis of HIV to lung cancer was significantly shorter for women. Although outcomes for lung cancer patients with HIV remain poor, high CD4 count is associated with an improved lung cancer-related survival.

Address correspondence to: Suresh S. Ramalingam, MD 1365 Clifton Road NE, Rm C-3090 Atlanta, GA 30322 suresh.ramalingam@emory.edu.

Presented as a poster at the $46^{\text {th }}$ Annual Meeting of the American Society of Clinical Oncology in Chicago, IL in June 2010 


\section{Keywords}

lung cancer; HIV; survival; anti-retroviral therapy; HAART

\section{Introduction}

The availability of highly antiretroviral therapy (HAART) since 1996 has improved AIDSrelated outcomes, transforming HIV from a rapidly lethal disease to a chronic illness [1]. While the incidence of HIV has reached a plateau, an estimated one million people in the United States have been infected as of 2006 and the numbers continue to rise [2]. As a result, non-AIDS-related contributing to the morbidity and mortality of HIV-infected patients [3]. Thirty percent of HIV-infected patients will develop cancer by the age of 60 in the post-HAART era [4]. The marked decline in AIDS-defining cancers (ADCs) that has accompanied the use of HAART has resulted in an increase in the proportion of non-AIDSdefining cancers (NADCs). The largest study to examine cancer incidence revealed that lung cancer represented 20\% of the 563 NADCs diagnosed from 1996 to 2002 [5]. Malignancies now account for a third of all HIV-related deaths, of which lung cancer is the leading cause of non-AIDS-defining cancer mortality [6,7].

HIV patients are 2-4 times more likely to develop lung cancer than the general population $[5,8,9]$. Although smoking remains an independent risk factor for lung cancer, it alone does not account for the increased incidence found in this population [10, 11]. In fact, organ transplant recipients on immunosuppressive agents have a lung cancer incidence rate comparable to that of HIV-infected patients, thus implicating a role for immunosuppression [12]. This is further substantiated by the association between the development of lung cancer and AIDS [5, 8]. However, single data point estimation of CD4 counts does not appear to be directly correlated to lung cancer incidence, a fact which may be attributed to the inherent variability of CD4 counts [5, 10]. Rather, the population range of CD4 levels, which correlates more accurately with the degree of immuosuppression seems to have an association [13]. A recent study has suggested that malignancy rates approach that of the general population in HIV patients with CD4 counts >500 [14]. Additional evidence has also implied that declining CD4 counts are associated with higher lung cancer risk and advanced stage disease at diagnosis $[13,15]$. While antiretroviral therapy (ARV) and its associated viral load suppression have not been shown to clearly impact lung cancer incidence, it may have an indirect effect by improving CD4 counts $[9,11,13,16]$.

HIV patients often present with advanced stage lung cancer at a younger age and have an inferior overall survival when compared to non-HIV patients with lung cancer [15]. While HAART has improved HIV-related outcomes, our understanding of its effect on the risk and clinical behavior of lung cancer is still evolving [15]. The current literature in the modern HAART era is sparse with regards to information about lung cancer, optimal treatment, and outcomes in HIV-infected patients. We therefore conducted a retrospective review of lung cancer in HIV positive patients treated at our institution to further characterize the clinical aspects of this population.

\section{Methods}

\section{Patient Population}

All HIV patients diagnosed with lung cancer from January 1995 to October 2008 were identified via ICD-9 codes and tumor registry at the Atlanta Veteran's Administration (VA) and Grady Memorial Hospital. HIV and primary lung cancer histology was confirmed in 80 patients. Individual patient charts and lab systems were reviewed for clinical data, 
specifically age, gender, race, sexual orientation, IV drug use history, smoking exposure, the date of HIV and cancer diagnosis, antiretroviral therapy (ARV) exposure, history of opportunistic infections, performance status, tumor pathology, AJCC $6^{\text {th }}$ edition TNM cancer stage at diagnosis, cancer treatment with associated complications, CD4 lymphocyte count, and HIV viral load at cancer diagnosis. Patient vital records were obtained from chart review and social security index. The protocol for this study was approved by the Institutional Review Board at Emory University.

\section{Statistical Analysis}

Pearson's correlation coefficients were estimated for each covariate studied: age at HIV diagnosis, age at cancer diagnosis, latency (time from HIV to cancer diagnosis), smoking, CD4 count at cancer diagnosis, cancer stage, and whether a patient received definitive treatment. CD4 count at diagnosis was treated as a continuous variable and also subcategorized into discrete variables using 3 different cutoff points $(50,200, \& 500 \mu \mathrm{l})$. The Kaplan-Meier method was used for cancer-related survival analysis using either the date of death or the date of data censorship (12/29/2009) if patients were still alive at the time of this analysis.

\section{Results}

\section{Patient Characteristics}

Eighty patients with HIV and primary lung cancer were identified for analysis within the Atlanta Veteran's Administration $(n=21)$ and Grady Memorial $(n=59)$ hospitals. Table 1 shows the patient characteristics for the cohort. The majority of patients in this cohort were males (80\%) and African American (84\%) with a median age of 52 years (range 28-73). About one-third of patients $(n=23)$ were either homosexual or bisexual. Seventy-one percent $(\mathrm{n}=54)$ used recreational drugs including marijuana and $25 \%(\mathrm{n}=19)$ were intravenous drug users. Excessive alcohol consumption was noted in $61 \%(n=49)$ of the study cohort. Twentyone patients had detailed histories and consumed $>4$ alcohol containing drinks/day; while the remaining 28 patients had a diagnosis of alcohol abuse, but detailed histories were not readily available. All 77 patients with documented smoking histories were smokers with an averageof 37 pack-years (range 10-100). Twenty patients were co-infected with hepatitis C and 8 with hepatitis B. In terms of other infectious comorbidities, past medical histories were significant for zoster $(n=16)$, latent tuberulosis $(n=15)$, disseminated mycobacterium $(n=8)$, clostridium difficile colitis $(n=5)$, and tuberculosis $(n=5)$. Twenty-seven patients were clinically diagnosed with recurrent bacterial pneumonias and 21 with pneumocystis jiroveci pneumonia. Patients were twice as likely to present with right-sided cancers than left-sided cancers and more than half of the primary tumors were located in the upper lobes. Seventythree patients had non-small cell lung cancer (NSCLC) of which $38 \%(n=30)$ was adenocarcinoma, 29\% ( $\mathrm{n}=23)$ squamous cell, and 25\% ( $\mathrm{n}=20)$ NSCLC unspecified. Most patients presented with advanced stage disease (74\% stage IIIB/IV vs. $20 \%$ stage I/II), however neither CD4 count nor a prior history of AIDS was associated with advanced stage disease. Almost half of the patients with stage IV disease presented with multiple nodules. Of the 7 patients with small cell lung cancer (SCLC), 5 patients presented with extensive stage disease.

Mean latency from diagnosis of HIV to lung cancer was 7 years (range 0-18) and was significantly shorter in women ( $4.1 \mathrm{yrs}$ vs. $7.7 \mathrm{yrs}, \mathrm{P}=0.02)$. Eight patients were diagnosed with HIV at the time of their cancer diagnosis, while the rest of the cohort had a diagnosis of HIV that preceded their cancer diagnosis. Patients who were diagnosed with HIV at a younger age were more likely to have a longer latency $(\rho=-0.47, p<0.0001)$. Table 2 shows the HIV-related characteristics of the patients in this cohort. At the time of cancer diagnosis, 
the mean CD4 count and viral load were $304 \mu \mathrm{L}$ (range 3-1361) and 82,420 copies/ml (range $<50$ to $>750,000)$, respectively. Smoking correlated with a higher CD4 count $(\rho=0.27$, $\mathrm{p}=0.02)$. Fifty-nine patients $(74 \%)$ had a previous diagnosis of AIDS, yet only $44(55 \%)$ had prior exposure to antiretroviral agents while $12(15 \%)$ others were initiated on ARVs after being diagnosed with lung cancer. Exposure to anti-retrovirals ranged from 1 to 12 regimens over a patient's lifetime which often involved modifications to 1 or 2 drugs within a regimen. Overall, patients received a median of 2 regimens with a maximum of 6 drugs at any given time. ARV therapy mainly consisted of a nucleotide reverse transcriptase inhibitors (NRTI) alone or in combination with non-nucleoside reverse transcriptase inhibitors (NNRTI) or protease inhibitors (PI). Only 2 patients were treated with a combination that included either an integrase or fusion inhibitor. The most common ARV regimens that a patient received included NRTI/NRTI/PI $(n=24)$, NRTI/PI/PI $(n=22)$, NRTI/ NRTI $(n=20)$, NRTI $(n=15)$, NRTI/NRTI/NNRTI $(n=13)$, or NRTI/NNRTI/PI/PI $(n=7)$. Seventeen patients $(27 \%)$ had an undetectable HIV viral load at the time of cancer diagnosis.

\section{Lung Cancer Treatment}

Lung cancer treatment-related parameters among the cohort are summarized in Table 3. Thirty-one of the 50 (62\%) evaluable patients had an Eastern Cooperative Oncology Group (ECOG) performance status of 0 or 1 . Fifty-three $(71 \%)$ patients received some form of anticancer therapy. Among those treated, 11 (21\%) underwent surgical resection, 15 (28\%) received combined modality therapy with chemotherapy and radiotherapy, $14(26 \%)$ received chemotherapy alone, and $13(25 \%)$ received palliative radiation only. Of those patients who were surgically resected, 1 had a wedge resection, 3 had right-sided pneumonectomy, and 7 had lobectomy. Poor performance status $(n=2)$ and acute infection $(n=2)$ prevented some patients from receiving treatment beyond palliative radiation alone, while others were not treated further either because they refused chemotherapy $(n=2)$ or for reasons not clearly documented $(n=7)$. Five patients declined all forms of anti-cancer therapy and 17 (22\%) patients were ineligible for treatment secondary to either poor performance status $(n=2)$, death prior to initiation of treatment $(n=8)$, or for reasons not clearly documented $(\mathrm{n}=7)$. A greater proportion $(76 \%)$ of treatment ineligible patients had a CD4 count $\leq 200$ compared to those who were definitively treated (30\%). Receiving cancerdirected therapy was significantly associated with ARV use $(\mathrm{p}=0.002)$ and a higher CD4 count ( $\mathrm{p}=0.02$ ) irrespective of a prior history of AIDS or CD4 count nadir (Table 4). Treated patients had a mean CD4 count of 349 vs. 183 in the untreated patients. Grade 3 or 4 toxicities occurred in $1 / 11(9 \%)$ patients undergoing surgical resection, $9 / 15(60 \%)$ receiving chemo-radiation, and 5/14 (36\%) receiving chemotherapy alone. One lobectomy was complicated by lung atelectasis, respiratory failure, and sepsis resulting in end stage renal disease. The most common complications included treatment delays secondary to neutropenia $(n=5)$, fever due to neutropenia $(n=5)$, infections unrelated to neutropenia $(n=4)$, radiation-related esophagitis $(n=6)$, and acute renal failure $(n=4)$. One patient died due to sepsis, acute renal failure, and respiratory failure following a dose of paclitaxel. Detailed treatment information is presented in Table 5. Patients with a previous history of AIDS were more likely to experience treatment-related complications when compared to those who merely had a CD4 count $\leq 200$. Five patients with NSCLC and 3 patients with SCLC received second-line chemotherapy after progression. Only 1 patient received third-line chemotherapy for SCLC.

\section{Lung Cancer-Related Outcomes}

The 1- and 3-year survival rates were $31 \%$ and $4 \%$ overall; $25 \%$ and $0 \%$ for patients with stage IIIB/IV disease; and 53\% and $8 \%$ for all treated patients, respectively. Overall, median survival of the whole cohort was 6.1 months. Median survival for patients with advanced stage (IIIB/IV) NSCLC was 4 months, which was significantly worse than for those who 
presented at earlier stages $(\mathrm{p}=0.0013)$. Patients with stage I had better survival rates compared to those with other stages (Figure 1). In a multivariate analysis after adjusting for gender, race, age, latency, CD4 count, and smoking pack-years; early stage disease ( $\mathrm{p}=0.03)$ and treatment vs. palliative radiation or no treatment $(\mathbf{p}=\mathbf{0 . 0 0 0 4})$ were associated with overall survival for patients with NSCLC (Table 6). CD4 count nadir, history of AIDS, ARV use, and histology did not affect overall survival. Lung cancer survival was significantly better for those patients with a CD4 count $>200(p=0.0298$, Figure 2$)$ and $>500$ $(\mathrm{p}=0.0076$, Figure 3$)$, but not for those stratified by a CD4 count of 50 (Figure 4$)$. When CD4 count was separated in quartiles $(<50,51-200,201-500,>500)$, those with a CD4 count $>500$ had a improved survival (Figure 5). However, CD4 count in the multivariate analysis was not a significant predictor of survival when adjusted for cancer stage. Patients who were treated with surgery or chemo-radiation had a significantly better survival compared to those who received palliative radiation or no treatment at all ( $p<0.0001$, Figure 6 ).

\section{Discussion}

In this large case series, we describe HIV patients with primary lung cancer in the postHAART era. Consistent with other case series [15, 17-23], patients in this cohort were predominantly younger male smokers (median age $52,80 \%$ males, and all smokers) many of whom presented with adenocarcinoma (38\%) and advanced stage disease (74\% stage IIIB/ IV). While immunosuppressed patients have a higher risk of developing lung cancer $[5,8$, 12, 13], HIV-infected patients who develop lung cancer are often characterized as having moderate immunosuppression. Although the majority of these patients (74\%) had a previous diagnosis of AIDS, the mean CD4 count was $304 \mu \mathrm{L}$ at the time of cancer diagnosis. Several studies have failed to demonstrate a direct correlation between absolute CD4 count and lung cancer risk, which may be partially attributed to CD4 count variability $[5,10,11,15,17$, 24-28]. In this study, we demonstrated that smoking is associated with a higher CD4 count as reported in other studies [29], supporting smoking as one of many factors that affect the absolute CD4 count.

Gender is another factor that may affect lung cancer risk. In the general population, women are more susceptible to the effects of smoking and to developing lung cancer with emerging evidence suggesting that estrogen may play a role [30-36]. Females in our cohort had a significantly shorter latency from HIV to lung cancer diagnosis than males (4.1 yrs vs. 7.7 yrs, $\mathrm{P}=0.02$ ) implicating that HIV-positive females may also be at greater risk for developing lung cancer. The Women's Interagency HIV Study (WIHS) supports the idea that women are at an increased risk for lung cancer irrespective of HIV status [37]. However, the retrospective nature of our study and its inherent biases could explain the difference seen in latency, especially if females either had a delay in HIV diagnosis or presented earlier with lung cancer.

Patients diagnosed with HIV at a younger age had a longer latency from HIV to lung cancer diagnosis. While this may imply that HIV positivity is a risk factor for lung cancer, the fact that $27 \%$ of the cohort had an undetectable viral load at cancer diagnosis suggests that this is likely a function of age rather than HIV infection itself. Ultimately, the duration of HIV positivity did not impact cancer-related survival. However, analysis of the cohort revealed that cancer stage, CD4 count, and treatment all affected overall survival. As in the general population, advanced cancer stages are associated with a poorer prognosis. Though patients with stage I disease clearly demonstrated an improved survival compared to stage IIIB/IV patients, small patient numbers may explain the unexpectedly low survival of patients with stage II lung cancer. Yet, overall outcomes were poor, with a 1-year survival of $25 \%$ and median survival of 4 months for patients with stage IIIB/IV disease. Although the 6.1-month median survival for all patients is comparable to that in other reported case studies, it is 
considerably worse than the expected 10-12 month median survival of lung cancer patients with the most advanced stage (IIIB/IV) in the general population $[38,39]$.

CD4 count and cancer-directed treatment may account for some of the discrepancy in overall lung cancer survival seen between HIV patients in this cohort and the general population. A high CD4 count $(>200 / 500 \mu \mathrm{L})$ in this cohort was associated with an improved lung cancer-related survival. However, when survival was analyzed in CD4 quartiles $(<50,51-200,201-500,>500)$, it appears that a favorable outcome was observed only in patients with a CD4 count $>500 \mu \mathrm{L}$, though the number of patients are small in each subset. Once adjusted for stage in the multivariate analysis, CD4 count was no longer a significant predictor of survival which suggests that cancer stage is a stornger predictor of outcome than CD4 count. Furthermore, patients who were treated had a significantly higher CD4 count $(349 \mu \mathrm{L})$ than those who were not treated $(183 \mu \mathrm{L})$. Brock et al. demonstrated a similar correlation between CD4 count and survival [15]. Therefore, it appears that patients with a lower CD4 count were more likely to be deemed ineligible for definitive cancerdirected therapy due to the presence of either other comorbidities or a poor performance status. In our series, poor performance status or other comorbidities prevented 28 (37\%) patients from being offered definitive therapy. Receiving definitive treatment had a greater impact on survival $(\mathbf{p = 0 . 0 0 0 4})$ in the multivariate analysis compared to those who only received palliative radiation or supportive care. Since systemic chemotherapy is associated with myelosuppression, it is conceivable that HIV-positive patients could be at higher risk for opportunistic infections during chemotherapy. This concern has often led to the use of suboptimal treatment regimens in this patient population. Furthermore, treatment data are limited to smaller case studies and the optimal treatment of lung cancer in HIV-positive patients is yet to be determined. Of those treated with chemotherapy or chemo-radiation about a third (9/29) developed an infection and one resulted in death. However, our data suggest that eligible patients benefit in terms of an improved survival from definitive treatment with manageable toxicities. A prior history of AIDS appeared to be more predictive of a treatment complication than merely having a CD4 count $<200$ alone. However, patient numbers were small, making definitive conclusions difficult to assess.

Lung cancer is the most fatal non-AIDS defining malignancy and frequently presents at an incurable stage [40]. While a CD4 count $<500$ is associated with a worse prognosis, it may only reflect the fact that treatment options are limited by associated co-morbid illness or a poor performance status. Future interventions need to focus on smoking prevention, early initiation of ARVs (CD4 count <500) and higher index of suspicion of lung cancer in patients with suggestive symptoms. It will also be important to evaluate the prevalence of certain molecular abnormalities such as epidermal growth factor receptor mutation, ALK translocation, K-ras and p53 mutations. This will allow for development of molecularly targeted therapeutic approaches for patients with HIV-related lung cancer. Prospective studies with commonly used therapeutic regimens are needed to further understand tolerability and efficacy outcomes. In summary, our study supports the use of stageappropriate standard therapeutic options for lung cancer in HIV-positive patients with a good performance status who do not have significant comorbidities.

\section{Acknowledgments}

Grant support: Supported by NIH P01 CA116676. TKO, DMS, WJC, FRK and SSR are Distinguished Cancer Scholars of the Georgia Cancer Coalition.

\section{References}

1. Palella FJ, et al. Declining Morbidity and Mortality among Patients with Advanced Human Immunodeficiency Virus Infection. N Engl J Med. 1998; 338(13):853-860. [PubMed: 9516219] 
2. Centers for Disease Control. HIV Prevalence Estimates-United States, 2006. MMWR. 2008; 57:1073-1076. [PubMed: 18830210]

3. Palella FJJMD, et al. Mortality in the Highly Active Antiretroviral Therapy Era: Changing Causes of Death and Disease in the HIV Outpatient Study. J Acquir Immune Defic Syndr. 2006; 43:27-34. [PubMed: 16878047]

4. Silverberg, M., et al. Trends in Cumulative Incidence of Cancer among HIV-infected Patients in North America. Conference on Retroviruses \& Opportunistic Infections (CROI); San Francisco, CA. 2010; p. Abstract 758

5. Engels EA, et al. Trends in cancer risk among people with AIDS in the United States 1980-2002. AIDS. 2006; 20(12):1645-1654. [PubMed: 16868446]

6. Bonnet F, et al. Changes in Cancer Mortality among HIV-Infected Patients: The Mortalite' 2005 Survey. Clinical Infectious Diseases. 2009; 48(5):633-639. [PubMed: 19202627]

7. Monforte A, A. D, Pradier C, et al. The Data Collection on Adverse Events of Anti, H. I. V. Drugs Study Group. HIV-induced immunodeficiency and mortality from AIDS-defining and non-AIDSdefining malignancies. AIDS. 2008; 22:2143-2153. [PubMed: 18832878]

8. Shiels MS, et al. A Meta-Analysis of the Incidence of Non-AIDS Cancers in HIV-Infected Individuals. JAIDS Journal of Acquired Immune Deficiency Syndromes. 2009; 52(5):611-622.

9. Patel P, et al. Incidence of Types of Cancer among HIV-Infected Persons Compared with the General Population in the United States, 1992-2003. Ann Intern Med. 2008; 148(10):728-736. [PubMed: 18490686]

10. Kirk, GregoryÂ D., et al. HIV Infection Is Associated with an Increased Risk for Lung Cancer, Independent of Smoking. Clinical Infectious Diseases. 2007; 45(1):103-110. [PubMed: 17554710]

11. Engels EA, et al. Elevated Incidence of Lung Cancer Among HIV-Infected Individuals. J Clin Oncol. 2006; 24(9):1383-1388. [PubMed: 16549832]

12. Grulich AE, et al. Incidence of cancers in people with HIV/AIDS compared with immunosuppressed transplant recipients: a meta-analysis. The Lancet. 2007; 370(9581):59-67.

13. Guiguet M, et al. Effect of immunodeficiency, HIV viral load, and antiretroviral therapy on the risk of individual malignancies (FHDH-ANRS CO4): a prospective cohort study. The Lancet Oncology. 2009; 10(12):1152-1159. [PubMed: 19818686]

14. Prosperi MCF, et al. Incidence of Malignancies in HIV-Infected Patients and Prognostic Role of Current CD4 Cell Count: Evidence from a Large Italian Cohort Study. Clinical Infectious Diseases. 2010; 50(9):1316-1321. [PubMed: 20297953]

15. Brock MV, et al. Delayed Diagnosis and Elevated Mortality in an Urban Population With HIV and Lung Cancer: Implications for Patient Care. JAIDS Journal of Acquired Immune Deficiency Syndromes. 2006; 43(1):47-55.

16. Silverberg, M.J.a., et al. Risk of cancers during interrupted antiretroviral therapy in the SMART study. AIDS. 2007; 21:1957-1963. [PubMed: 17721103]

17. Sridhar KS, et al. Lung cancer in patients with human immunodeficiency virus infection compared with historic control subjects. Chest. 1992; 102(6):1704-1708. [PubMed: 1446476]

18. Vyzula R, Remick SC. Lung cancer in patients with HIV-infection. Lung Cancer. 1996; 15(3): 325-339. [PubMed: 8959678]

19. Tirelli U, et al. Lung carcinoma in 36 patients with human immunodeficiency virus infection. Cancer. 2000; 88(3):563-569. [PubMed: 10649248]

20. Alshafie MT, Donaldson B, Oluwole SF. Human immunodeficiency virus and lung cancer. British Journal of Surgery. 1997; 84(8):1068-1071. [PubMed: 9278642]

21. Spano J-P, et al. Lung cancer in patients with HIV infection and review of literature. Medical Oncology. 2004; 21(2):109-115. [PubMed: 15299182]

22. Lavolé A, et al. Effect of highly active antiretroviral therapy on survival of HIV infected patients with non-small-cell lung cancer. Lung Cancer. 2009; 65(3):345-350. [PubMed: 19135758]

23. Bertolaccini L, et al. Clinical characteristic lung cancer in HIV-infected patients. Cancer Therapy. 2008; 6:903-906. 
24. Clifford GM, et al. Cancer Risk in the Swiss HIV Cohort Study: Associations With Immunodeficiency, Smoking, and Highly Active Antiretroviral Therapy. J. Natl. Cancer Inst. 2005; 97(6):425-432. [PubMed: 15770006]

25. Mbulaiteye SM, et al. Immune Deficiency and Risk for Malignancy Among Persons with AIDS. JAIDS Journal of Acquired Immune Deficiency Syndromes. 2003; 32(5):527-533.

26. Bedimo RJ, et al. Incidence of Non-AIDS-Defining Malignancies in HIV-Infected Versus Noninfected Patients in the HAART Era: Impact of Immunosuppression. JAIDS Journal of Acquired Immune Deficiency Syndromes. 2009; 52(2):203-208.

27. Tenholder MF, Jackson HD. Bronchogenic carcinoma in patients seropositive for human immunodeficiency virus. Chest. 1993; 104(4):1049-1053. [PubMed: 8404164]

28. Chaturvedi AK, et al. Elevated risk of lung cancer among people with AIDS. AIDS. 2007; 21(2): 207-213. [PubMed: 17197812]

29. Marshall M, McCormack M, Kirk G. Effect of cigarette smoking on HIV acquisition, progression, and mortality. AIDS Educ Prev. 2009; 2009(21 (3 suppl)):28-39. [PubMed: 19537952]

30. International Early Lung Cancer Action Program Investigators. Women's Susceptibility to Tobacco Carcinogens and Survival After Diagnosis of Lung Cancer. JAMA. 2006; 296(2):180 184. [PubMed: 16835423]

31. Claudia IH, Olli SM. Women's susceptibility to tobacco carcinogens. Lung cancer (Amsterdam, Netherlands). 2004; 43(1):1-5.

32. Risch HA, et al. Are Female Smokers at Higher Risk for Lung Cancer than Male Smokers?: A Case-Control Analysis by Histologic Type. Am. J. Epidemiol. 1993; 138(5):281-293. [PubMed: 8395141]

33. HARRIS RE, et al. Race and Sex Differences in Lung Cancer Risk Associated with Cigarette Smoking. Int. J. Epidemiol. 1993; 22(4):592-599. [PubMed: 8225730]

34. Márquez-Garbán DC, et al. Estrogen receptor signaling pathways in human non-small cell lung cancer. Steroids. 2007; 72(2):135-143. [PubMed: 17276470]

35. Ganti AK, et al. Hormone Replacement Therapy Is Associated With Decreased Survival in Women With Lung Cancer. J Clin Oncol. 2006; 24(1):59-63. [PubMed: 16314616]

36. Slatore CG, et al. Lung Cancer and Hormone Replacement Therapy: Association in the Vitamins and Lifestyle Study. J Clin Oncol. 2010; 28(9):1540-1546. [PubMed: 20159813]

37. Levine AM, et al. HIV As a Risk Factor for Lung Cancer in Women: Data From the Women's Interagency HIV Study. J Clin Oncol. 2010; 28(9):1514-1519. [PubMed: 20177022]

38. Schiller JH, et al. Comparison of Four Chemotherapy Regimens for Advanced Non-Small-Cell Lung Cancer. N Engl J Med. 2002; 346(2):92-98. [PubMed: 11784875]

39. Scagliotti GV, et al. Phase III Study Comparing Cisplatin Plus Gemcitabine With Cisplatin Plus Pemetrexed in Chemotherapy-Naive Patients With Advanced-Stage Non-Small-Cell Lung Cancer. J Clin Oncol. 2008; 26(21):3543-3551. [PubMed: 18506025]

40. Lewden C, et al. Changes in Causes of Death Among Adults Infected by HIV Between 2000 and 2005: The "Mortalite 2000 and 2005" Surveys (ANRS EN19 and Mortavic). J Acquir Immune Defic Syndr. 2008; 48(5):590-598. [PubMed: 18645512] 


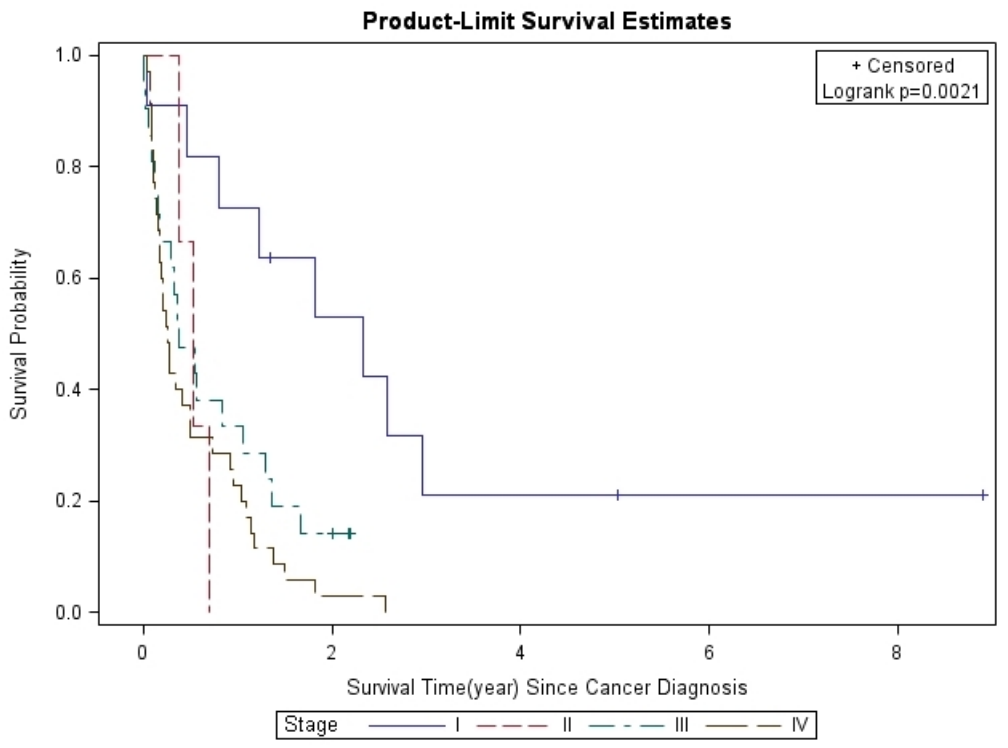

Figure 1. Lung Cancer Survival Based on Stage Lung cancer survival was analyzed by the Kaplan-Meier method for different stages (I-IV) of NSCLC at diagnosis. 


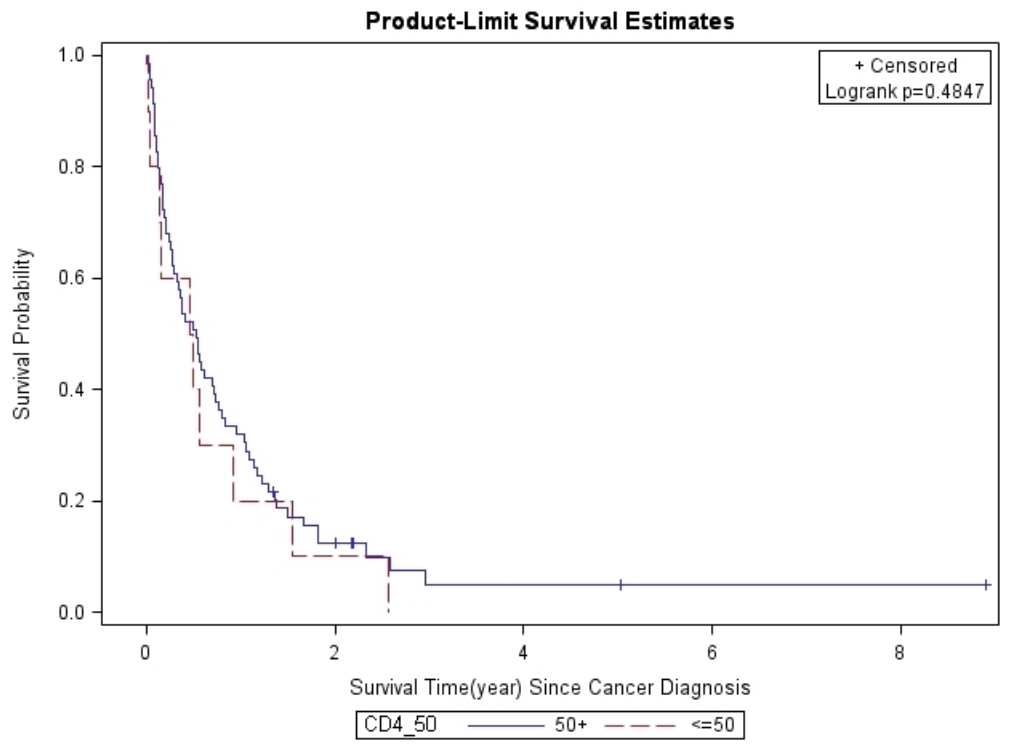

Figure 2. CD4 Count at Cancer Diagnosis ( $\leq 50$ vs. 50+)

Lung cancer survival was stratified by CD4 count at cancer diagnosis, and analyzed by the Kaplan-Meier method. 


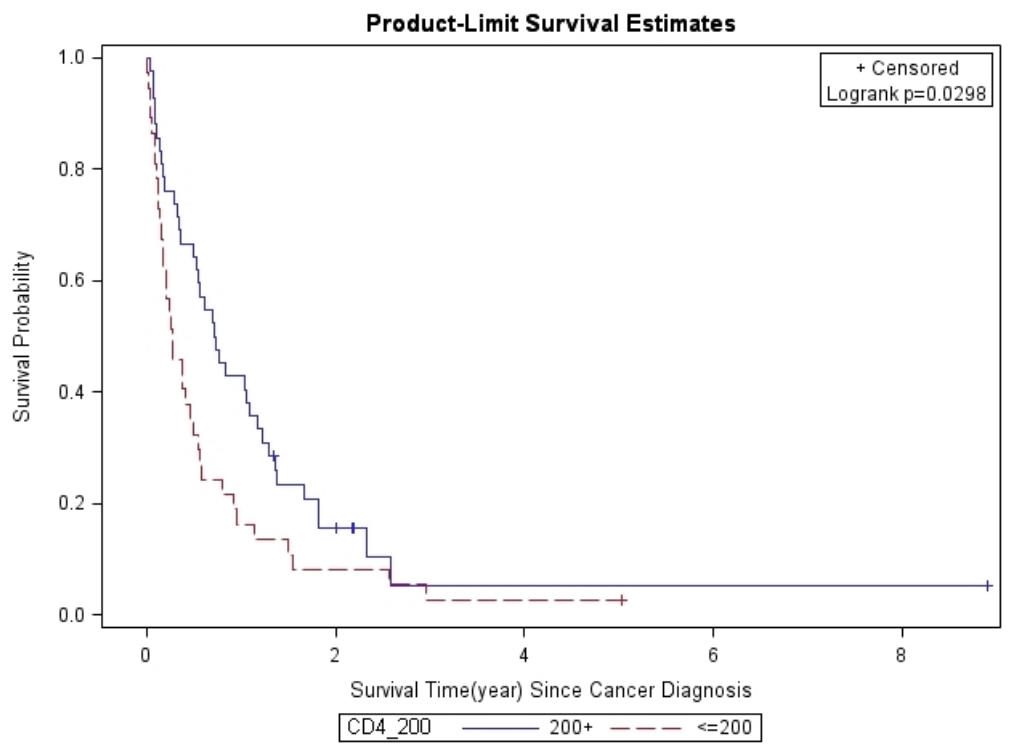

Figure 3. CD4 Count at Cancer Diagnosis ( $\leq 200$ vs. 200+)

Lung cancer survival was stratified by CD4 count at cancer diagnosis, and analyzed by the Kaplan-Meier method. 


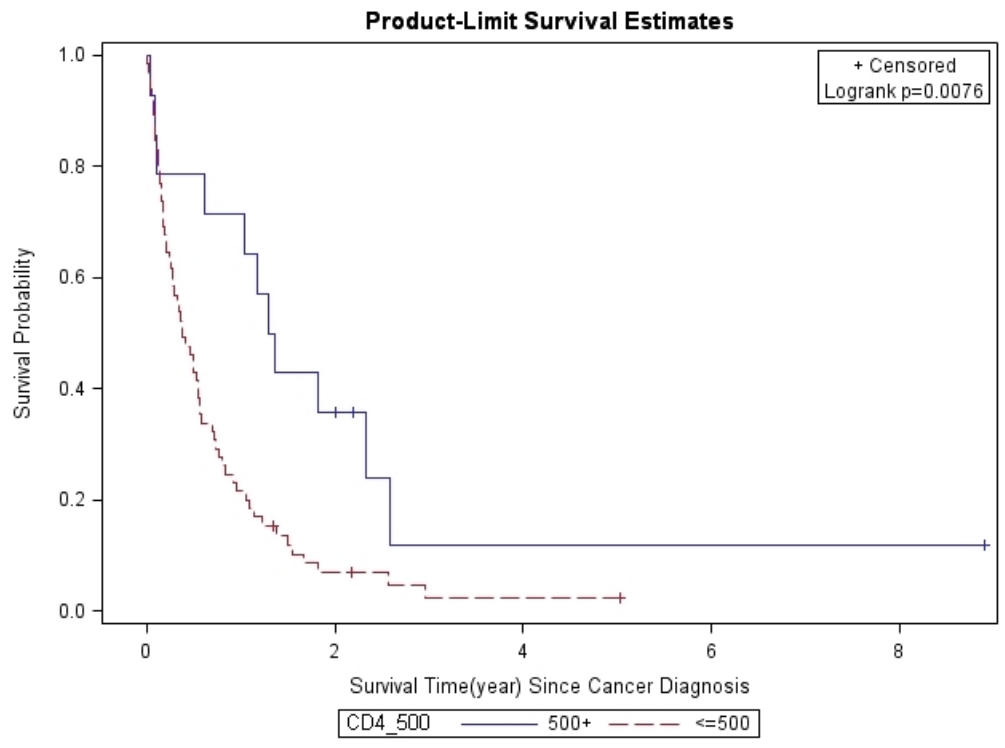

Figure 4. CD4 Count at Cancer Diagnosis ( $\leq 500$ vs. 500+)

Lung cancer survival was stratified by CD4 count at cancer diagnosis, and analyzed by the Kaplan-Meier method. 


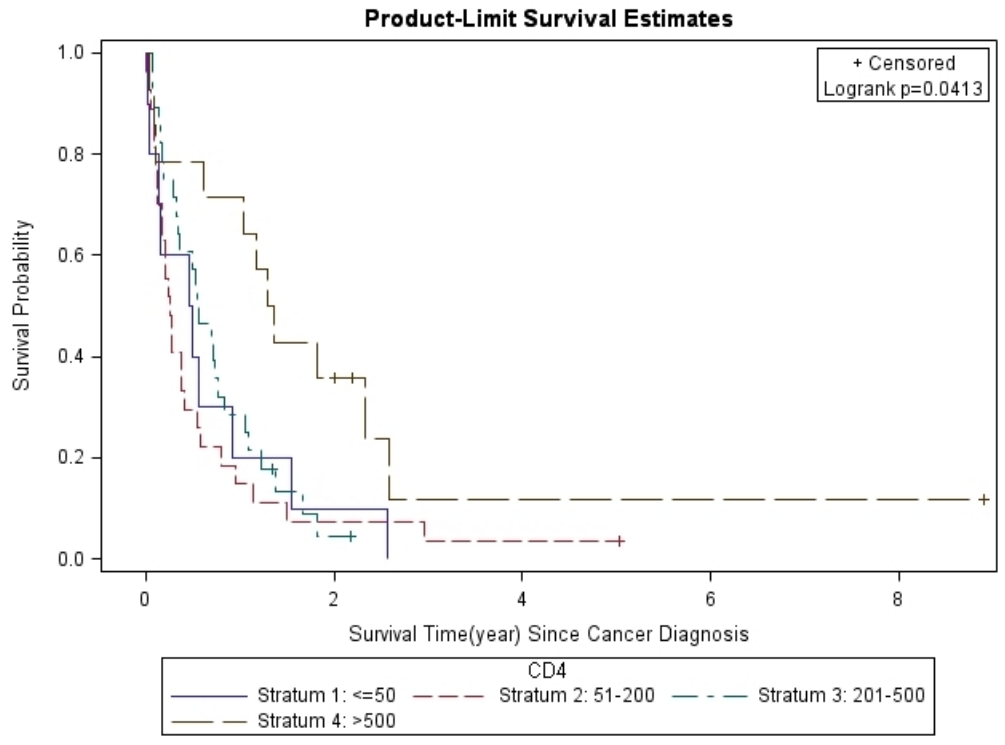

Figure 5. Lung Cancer Survival Based on CD4 Count

Lung cancer survival was stratified by CD4 count $(<50,51-200,201-500,>500)$ at cancer diagnosis and analyzed by the Kaplan-Meier method. 


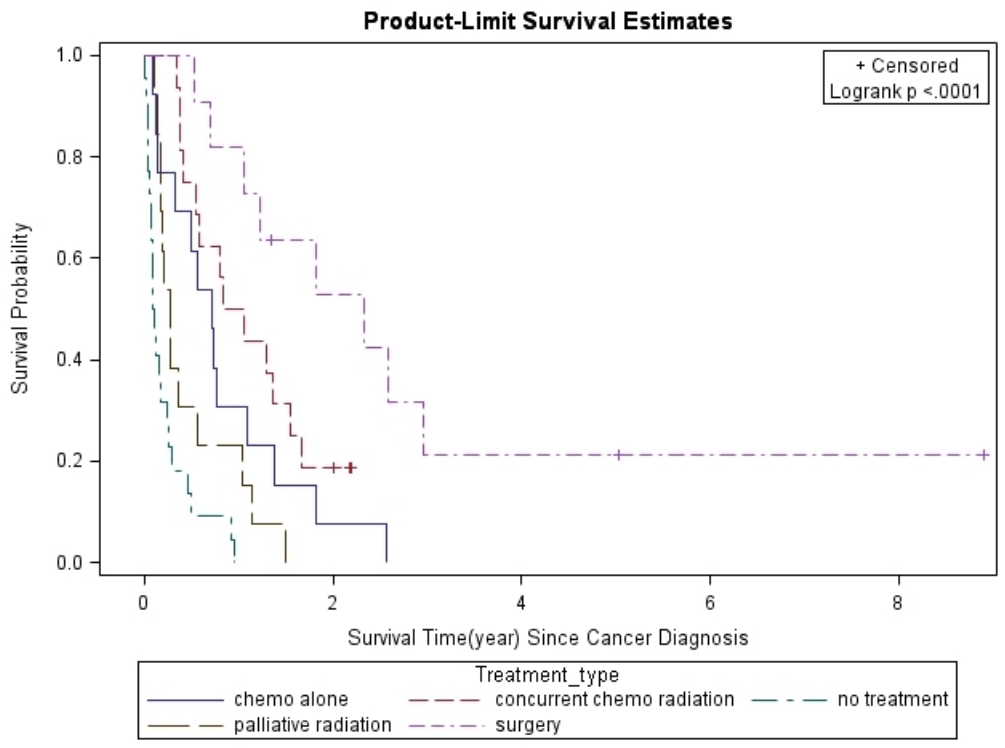

Figure 6. Lung Cancer Survival Based on Treatment Modality

Lung cancer survival was analyzed by the Kaplan-Meier method for different treatment modalities. 
Table 1

Patient Characteristics

\begin{tabular}{|c|c|}
\hline Patient Characteristics & Results N (\%) \\
\hline Median Age/Range (years), $\mathrm{N}=80$ & $52 / 28-73$ \\
\hline Males, $\mathrm{N}=80$ & $64(80)$ \\
\hline African Americans, $\mathrm{N}=80$ & $67(84)$ \\
\hline Smoking, Mean pack-years/Range, $\mathrm{N}=77$ & $37 / 10-100$ \\
\hline \multicolumn{2}{|l|}{ Sexual Orientation, $N=69$} \\
\hline Heterosexual & $46(67)$ \\
\hline Men who have sex with Men & $13(19)$ \\
\hline Bisexual & $10(14)$ \\
\hline Intravenous Drug Use, $\mathrm{N}=76$ & $19(25)$ \\
\hline Substance abuse (any), N=76 & $54(71)$ \\
\hline Alcohol abuse, $\mathrm{N}=80$ & $49(61)$ \\
\hline $\begin{array}{l}\text { Mean Latency of HIV to Lung Ca Diagnosis/ Range } \\
\text { (years), N=80 }\end{array}$ & $7 / 0-18$ \\
\hline \multicolumn{2}{|l|}{ Histology, $\mathrm{N}=80$} \\
\hline Small Cell Lung Cancer & $7(9)$ \\
\hline Non-small Cell Lung Cancer & $73(91)$ \\
\hline Adenocarcinoma & $30(38)$ \\
\hline Squamous & $23(29)$ \\
\hline NSCLC NOS & $20(25)$ \\
\hline \multicolumn{2}{|l|}{ Stage at Diagnosis } \\
\hline \multicolumn{2}{|l|}{ SCLC, $N=7$} \\
\hline Limited & $2(28)$ \\
\hline Extensive & $5(71)$ \\
\hline \multicolumn{2}{|l|}{ NSCLC, N=70 } \\
\hline IA & $3(4)$ \\
\hline IB & $8(11)$ \\
\hline IIA & 0 \\
\hline IIB & $3(4)$ \\
\hline IIIA & $3(4)$ \\
\hline IIIB & $18(25)$ \\
\hline IV & $35(49)$ \\
\hline
\end{tabular}

$\mathrm{N}=$ number of patients with available data. $\mathrm{Ca}=\mathrm{Cancer}, \mathrm{NSCLC}=$ Non-small cell lung cancer, NOS=Not otherwise specified, SCLC=Small cell lung cancer 
Table 2

HIV Related Factors

\begin{tabular}{|l|l|}
\hline Patient Characteristics & Results N (\%) \\
\hline Mean CD4 at CA diagnosis/Range $(\mu \mathrm{L}), \mathrm{N}=79$ & $304 / 3-1361$ \\
\hline Mean VL at CA diagnosis/Range (copies/ml), N=61 & $82,420 /<50->750,000$ \\
\hline Viral Load (VL) undetectable & $17(27)$ \\
Viral Load $\geq 200,000$ & $7(11)$ \\
\hline AIDS diagnosed prior to CA diagnosis, N=80 & $59(74)$ \\
\hline Antiretroviral use, N=80 & $44(55)$ \\
Initiated prior to CA diagnosis & $12(15)$ \\
Initiated after CA diagnosis & $24(30)$ \\
None &
\end{tabular}

$\mathrm{N}=$ number of patients with available data. $\mathrm{CA}=\mathrm{Cancer}, \mathrm{VL}=\mathrm{Viral}$ load. 
Table 3

\section{Lung Cancer Treatment}

\begin{tabular}{|c|c|}
\hline Patient Characteristics & Result N (\%) \\
\hline ECOG performance status, $\mathrm{N}=50$ & \\
\hline $0-1$ & $31(62)$ \\
\hline$\geq 2$ & $19(38)$ \\
\hline Treatment, $\mathrm{N}=75$ & $53(71)$ \\
\hline Surgery & $11(21)$ \\
\hline Concurrent chemo-radiation & $15(28)$ \\
\hline Chemotherapy alone & $14(26)$ \\
\hline Radiation alone & $13(25)$ \\
\hline WBXRT only & $5(9)$ \\
\hline No Treatment, $N=75$ & $22(29)$ \\
\hline Ineligible for Treatment & $17(77)$ \\
\hline Declined Treatment & $5(23)$ \\
\hline CD4 <200 in Treated Patients, $N=75$ & $12 / 40(30)$ \\
\hline Surgery & $2 / 11(20)$ \\
\hline Concurrent chemo-radiation & $6 / 15(40)$ \\
\hline Chemotherapy alone & $4 / 14(29)$ \\
\hline Treatment Ineligible, $\mathrm{N}=75$ & $17(23)$ \\
\hline CD4 $<200$ & $13(76)$ \\
\hline Treatment complication, $\mathrm{N}=75$ & $14 / 40(35)$ \\
\hline Surgery & $1 / 11(9)$ \\
\hline $\mathrm{CD} 4 \leq 200$ & $0 / 2$ \\
\hline Prior diagnosis of AIDS & 1 \\
\hline Concurrent chemo-radiation & $9 / 15(60)$ \\
\hline $\mathrm{CD} 4 \leq 200$ & $3 / 6$ \\
\hline Prior diagnosis of AIDS & 7 \\
\hline Chemotherapy alone & $5 / 14(36)$ \\
\hline $\mathrm{CD} 4 \leq 200$ & $3 / 4$ \\
\hline Prior diagnosis of AIDS & 5 \\
\hline
\end{tabular}

$\mathrm{N}=$ number of patients with available data. WBXRT=Whole brain radiation. 
Table 4

Factors Affecting Cancer Directed Therapy

\begin{tabular}{|c|c|c|c|}
\hline & \multicolumn{2}{|c|}{ Cancer Directed Therapy } & \multirow[t]{2}{*}{ p-value } \\
\hline & Yes & No & \\
\hline $\begin{array}{l}\text { Antiretroviral use (ARV) } \\
\text { Yes } \\
\text { No }\end{array}$ & $\begin{array}{l}43 \\
(81 \%) \\
10 \\
(19 \%)\end{array}$ & $\begin{array}{l}10 \\
(45 \%) \\
12 \\
(55 \%)\end{array}$ & 0.002 \\
\hline $\begin{array}{l}\text { AIDS Onset prior to Cancer } \\
\text { Diagnosis } \\
\text { Yes } \\
\text { No }\end{array}$ & $\begin{array}{l}39 \\
(74 \%) \\
14 \\
(26 \%)\end{array}$ & $\begin{array}{l}18 \\
(82 \%) \\
4 \\
(18)\end{array}$ & 0.56 \\
\hline $\begin{array}{l}\text { CD4 Count Mean } \\
\text { (standard error) }\end{array}$ & $\begin{array}{l}348.8 \\
(40.4)\end{array}$ & $\begin{array}{l}183.4 \\
(51.7)\end{array}$ & 0.02 \\
\hline $\begin{array}{l}\text { CD4 Count Nadir } \\
\leq 200 \\
>200\end{array}$ & $\begin{array}{l}43 \\
(83 \%) \\
9 \\
(17 \%)\end{array}$ & $\begin{array}{l}18 \\
(82 \%) \\
4 \\
(18)\end{array}$ & 0.93 \\
\hline
\end{tabular}


Table 5

First-line Treatment and Treatment-related Complications for Individual Patients

\begin{tabular}{|c|c|c|}
\hline \multicolumn{2}{|c|}{ Treatment (dose mg/m2) } & Treatment Complications \\
\hline \multicolumn{3}{|c|}{ Limited Stage Small Cell Lung } \\
\hline 1 & Cisplatin/VP16 $\times 2 \mathrm{c}$ & Fever with neutropenia \\
\hline \multicolumn{3}{|c|}{ Extensive Stage Small Cell Lung } \\
\hline 2 & Cisplatin $(60) / \mathrm{VP} 16(75) \times 1 \mathrm{c}$ & Decline in PS \\
\hline \multirow[t]{2}{*}{3} & Cisplatin(75)/ VP16(100) $\times 3 \mathrm{c}$ & ARF, clostridium difficile \\
\hline & $\begin{array}{l}\text { Cisplatin }(60) / \text { VP16(120) } \times 1 \mathrm{c}->(75) /(100) \times 1 \mathrm{c}->(75) /(80) \times 2 \mathrm{c} \\
+ \text { XRT(30Gy) }\end{array}$ & Pericarditis, Prolonged neutropenia \\
\hline 4 & Cisplatin(75)/VP16(100) $\times 4 \mathrm{c}$ & Prolonged neutropenia \\
\hline \multicolumn{3}{|c|}{ Stage II Non-small Cell Lung Cancer } \\
\hline 5 & Cisplatin(50)/VP16(50) $\times 2 \mathrm{c}+\mathrm{XRT}$ & Pseudomonas bacteremia \\
\hline 6 & Cisplatin + XRT & \\
\hline \multicolumn{3}{|c|}{ Stage III Non-small Cell Lung Cancer } \\
\hline 7 & Carboplatin(AUC 6)/Paclitaxel(175) $\times 2 \mathrm{c}+\mathrm{XRT}(37 \mathrm{~Gy})->1$ & \\
\hline 8 & Carboplatin (AUC 1.5)/Paclitaxel(50) $\times 5$ wkly c + XRT->1 c & Prolonged neutropenia \\
\hline 9 & Cisplatin(50)/VP16(100)× $2 \mathrm{c}+\mathrm{XRT}(34 \mathrm{~Gy})$ & \\
\hline 10 & $\begin{array}{l}\text { Cisplatin(50)/VP16(50) × } 1 \text { c->Carboplatin(AUC 2) } \times 3 \text { wkly c + } \\
\text { XRT(66Gy) }\end{array}$ & $\begin{array}{l}\text { Fever with neutropenia, ARF, decline in PS, } \\
\text { pneumonia }\end{array}$ \\
\hline 11 & Cisplatin(50)/VP16(50) $\times 2 \mathrm{c}+\mathrm{XRT}(66 \mathrm{~Gy})$ & \\
\hline 12 & Cisplatin(75)/ (100)× 1->XRT(61 Gy) & Myelosuppression, ARF \\
\hline 13 & Carboplatin/Paclitaxel $\times 4 \mathrm{c}+\mathrm{XRT}$ & Esophagitis requiring gastric tube \\
\hline 14 & Carboplatin/Paclitaxel $\times 6$ wkly $\mathrm{c}+\mathrm{XRT}(66 \mathrm{~Gy})->3 \mathrm{c}$ & Esophagitis, dehydration, pneumonia \\
\hline 15 & Carboplatin(AUC 5)/Paclitaxel(135) $\times 1 \mathrm{c}$ & Neutropenia, hypotension \\
\hline 16 & Cisplatin $\times 4$ wkly $\mathrm{c}+\mathrm{XRT}$ & Esophagitis \\
\hline 17 & Carboplatin(AUC 5)/Paclitaxel(175) $\times 2 \mathrm{c}+\mathrm{XRT}(66 \mathrm{~Gy})->2 \mathrm{c}$ & Syncope, esophagitis \\
\hline \multicolumn{3}{|c|}{ Stage IV Non-small Cell Lung Cancer } \\
\hline 18 & Carboplatin/Paclitaxel $\times 4 \mathrm{c}$ & \\
\hline 19 & Cisplatin(30) wkly c + XRT(37.5 Gy)->Paclitaxel $\times 1 \mathrm{c}$ & $\begin{array}{l}\text { Esophagitis, ITP/hemoptysis, aspergillosis/VRE } \\
\text { sepsis, ARF, respiratory failure and death }\end{array}$ \\
\hline 20 & Carboplatin(AUC 6)/Paclitaxel(200) $\times 2$ c & Esophagitis \\
\hline 21 & Carboplatin(Auc 2)/Paclitaxel(45)×7 wkly c + XRT(57 Gy) & Prolonged neutropenia, esophagitis \\
\hline 22 & Carboplatin/Paclitaxel $\times 4 \mathrm{c}$ & \\
\hline 23 & Carboplatin/Paclitaxel $\times 1 \mathrm{c}$ & \\
\hline 24 & Carboplatin/Paclitaxel $\times 5 \mathrm{c}$ & \\
\hline 25 & Carboplatin(AUC 5)/Paclitaxel(175) $\times 4 \mathrm{c}$ & Zoster, symptomatic anemia \\
\hline 26 & Carboplatin/Paclitaxel $\times 4 \mathrm{c}$ & \\
\hline
\end{tabular}

VP16=Etoposide, $c=c y c l e s, P S=$ performance status, $\mathrm{ARF}=$ acute renal failure, ITP=immune thrombocytopenia, VRE=vancomycin resistant enterococcus 
Table 6

Multivariate Analysis of Cancer-Related Overall Survival and Prognostic Factors

\begin{tabular}{|c|c|c|c|}
\hline Variable & Categorical variables & $\begin{array}{l}\text { Hazard Ratio } \\
(95 \% \text { CI })\end{array}$ & p-value \\
\hline \multicolumn{2}{|c|}{ Age at Cancer Diagnosis } & $\begin{array}{c}0.993 \\
(0.959,1.029)\end{array}$ & 0.7079 \\
\hline \multicolumn{2}{|c|}{ Smoking (pack-year) } & $\begin{array}{c}1.015 \\
(0.997,1.032)\end{array}$ & 0.0949 \\
\hline \multicolumn{2}{|l|}{ Latency } & $\begin{array}{c}0.998 \\
(0.941,1.058)\end{array}$ & 0.9413 \\
\hline \multicolumn{2}{|c|}{ CD4 at Cancer Diagnosis } & $\begin{array}{c}0.999 \\
(0.998,0.99999)\end{array}$ & 0.1571 \\
\hline \multirow[t]{2}{*}{ Gender: } & Female & $\begin{array}{c}1.064 \\
(0.521,2.174)\end{array}$ & 0.8646 \\
\hline & Male & Reference & \\
\hline \multirow[t]{2}{*}{ Race } & African American & $\begin{array}{c}1.054 \\
(0.420,2.643)\end{array}$ & 0.9114 \\
\hline & White & Reference & \\
\hline \multirow[t]{4}{*}{ Stage } & I & $\begin{array}{c}0.227 \\
(0.079,0.652)\end{array}$ & \multirow[t]{4}{*}{0.03} \\
\hline & II & $\begin{array}{c}1.436 \\
(0.359,5.745)\end{array}$ & \\
\hline & III & $\begin{array}{c}1.012 \\
(0.492,2.081)\end{array}$ & \\
\hline & IV & Reference & \\
\hline \multirow[t]{2}{*}{ Treatment } & $\begin{array}{l}\text { No treatment or } \\
\text { Palliative radiation }\end{array}$ & $\begin{array}{c}4.169 \\
(1.893,9.181)\end{array}$ & 0.0004 \\
\hline & Treated & Reference & \\
\hline
\end{tabular}

